\title{
Mass nesting of olive ridley sea turtles Lepidochelys olivacea at La Escobilla, Mexico: linking nest density and rates of destruction
}

\author{
M. Ocana ${ }^{1, *}$, M. Harfush-Melendez ${ }^{2}$, S. S. Heppell ${ }^{1}$ \\ ${ }^{1}$ Dept. of Fisheries and Wildlife, Oregon State University, Corvallis, Oregon 97331, USA \\ ${ }^{2}$ Centro Mexicano de la Tortuga, CONANP, SEMARNAT, Mazunte, Oaxaca 70946, Mexico
}

\begin{abstract}
Olive ridley sea turtles Lepidochelys olivacea exhibit synchronized nesting behavior that affects egg survival through a variety of mechanisms, including intra-specific nest destruction. This activity is difficult to quantify due to the frequency of arribadas (mass nesting events that occur over several days) and temporal overlap of incubation periods. We hypothesized that nest destruction is positively related to cumulative nest density. We quantified these variables through direct observation of nesting by 1293 turtles in 26 plots (each $9 \mathrm{~m}^{2}$ ) during 2 arribadas at La Escobilla, Mexico, in 2009. Cumulative nest densities ranged from 1 to 8 nests $\mathrm{m}^{-2}$. The proportion of turtles observed destroying eggs was used as a proxy for nest destruction. A total of 5.12 and $23.10 \%$ of turtles destroyed eggs in the first and second arribadas, respectively. We used a mixed model logistic regression to determine that the odds of destruction (or the probability that a turtle destroys eggs divided by the probability that she does not) increased $21 \%$ for every additional nest per square meter. We could not measure total egg survival as a function of nest density likely due to extreme weather conditions and beetle predation that resulted in $0 \%$ hatchling production over most of the study area in August to October 2009. However, understanding the relationship between nest density and the probability of nest destruction is an important first step toward quantifying density dependence in olive ridleys. We recommend that monitoring plans include standardized measurements of density (nests per square meter) and destruction levels to improve estimates of annual hatchling production.
\end{abstract}

KEY WORDS: Olive ridley sea turtle $\cdot$ Lepidochelys olivacea $\cdot$ Arribada $\cdot$ Density $\cdot$ Nest destruction $\cdot$ La Escobilla $\cdot$ Density dependence

\section{INTRODUCTION}

Intra-specific density-dependent factors affect population dynamics in a variety of taxa (see Brook \& Bradshaw 2006 for a review). Understanding the mechanisms that lead to density dependence is important for conservation of protected species because of the pressing need to develop scientifically sound approaches to increase abundance and distribution. Density impacts are demonstrated in aggregations of nest-building taxa, such as salmonids and sea turtles, where high densities of females and nests can affect egg survival (Cornelius et al. 1991, Sandercock 1991, Honarvar et al. 2008). Density-dependent cohort production from aggregate nesting can ultimately lead to variability in population age structure and population cycles (Higgins et al. 1997).

Ridley sea turtles aggregate to form remarkable mass nesting events ('arribadas') that occur at only a few beaches worldwide. During olive ridley Lepi- 
dochelys olivacea arribadas, 1000s of females gather to synchronously nest over a few consecutive nights (and up to several weeks) (Bernardo \& Plotkin 2007). The largest arribadas number from 10 s to 100 s of 1000s of turtles at La Escobilla (Mexico), Ostional (Costa Rica) and along the coast of Orissa (India) (Bernardo \& Plotkin 2007). Arribada dynamics are complex, with many factors that may affect nest survival (Fig. 1). High nest density is believed to negatively impact nest success through interrelated factors, such as microclimate variations and likelihood of predation. One often observed factor is intra-specific nest destruction, which is defined as the damage of previously laid eggs by later-nesting females. In addressing the evolution of arribadas, Bernardo \& Plotkin (2007) hypothesized a functional relationship between the probability of nest success and nest density in which a more or less exponential increase in nest destruction occurs with increasing nest density. Further, they theorized that predation trumps the role of nest destruction in driving nest mortality until high nest densities are reached, at which point destruction becomes a dominant factor. Investigating the relationship between nest density and each potential factor that could impact survival, such as those mentioned above, is the first step to understanding what ultimately determines nest success.

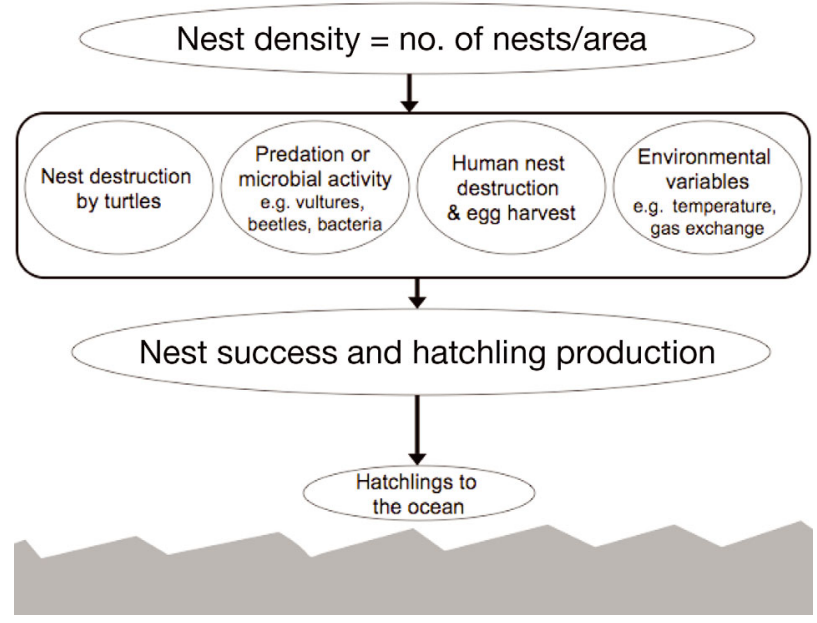

Fig. 1. Simplified diagram of factors affecting productivity at olive ridley Lepidochelys olivacea arribada nesting beaches. Note that nest density may act on hatchling production via a number of potential routes, which, in turn, may affect each other. For example, nest destruction might increase microbial activity, which could affect oxygen gas exchange. The present study focused on the potential of high nest density to result in high levels of nest destruction (later-nesting females destroying eggs from previously laid viable nests)
Although Bernardo and Plotkin provided the above hypotheses, previously published studies have not jointly examined intra-specific nest destruction and nest density at arribada beaches, perhaps owing to the difficulty of working with turtles in situ and quantifying nest density across space and time. However, previous research on sea turtle species at non-arribada beaches has examined the density-destruction relationship directly (Tiwari et al. 2006), and other studies have separately assessed the effects of either nest destruction or density at arribada (Cornelius et al. 1991, Honarvar et al. 2008) and non-arribada beaches (Bustard \& Tognetti 1969, Girondot et al. 2002, Caut et al. 2006, Tiwari et al. 2010). For example, density-dependent impacts on nests have been empirically demonstrated in artificially manipulated nesting conditions; significantly lower hatching success occurred in high-density plots compared to low- or mediumdensity ones, likely due to interactions with temperature and gas exchange (Honarvar et al. 2008). In a seminal study of arribada destruction, eggs from a higher percentage of marked nests were damaged in larger arribadas and nest destruction increased in each successive night of an arribada and with each subsequent arribada in the season (Cornelius et al. 1991). Further studies that quantify levels of destruction at varying densities could improve the science behind management decisions at high-density nesting beaches, especially ones that consider nest removal to reduce density impacts.

Given the complexity of arribada nesting and logistical challenges of monitoring waves of nesting females that arrive nightly, managers may encounter difficulties in identifying how to focus research efforts and which variables to measure. Currently, government researchers at La Escobilla, Mexico, estimate the total number of nests using the Gates-Valverde transect count method (Gates et al. 1996). With an estimated 1.16 million nests in 2009/2010 making it one of the largest arribada nesting populations in the world, La Escobilla is an ideal location to consider potentially density-dependent determinants of nest success. In the present study, we provide the next logical step and build on previous work by explicitly focusing on the relationship between nest density and nest destruction behavior by individual females. We tested the hypothesis that nest destruction is positively related to nest density by directly observing turtle behavior over the course of 2 arribadas, and quantified naturally occurring nest densities and destruction in space and time. 


\section{MATERIALS AND METHODS}

\section{Study site}

La Escobilla is a $7 \mathrm{~km}$ beach located on the Pacific coast of Oaxaca, Mexico (Fig. 2). It is primarily utilized by olive ridley turtles Lepidochelys olivacea and the most frequently used nesting area is divided laterally into $100 \mathrm{~m}$ wide stations with markers every $50 \mathrm{~m}$. The beach is part of a national sanctuary that has been monitored by the Mexican government since 1967 (Marquez et al. 2001). Despite the beach's remoteness, there is considerable activity by various groups of people: biologists and volunteers with the Mexican Sea Turtle Center, armed Marines and government law enforcers, community members, and poachers illegally harvesting eggs. Aside from illegal egg harvest, other potential causes of nest failure at this site include predation (e.g. dogs, vultures, beetles, crabs), water inundation (particularly in areas near the estuaries), extreme environmental conditions (e.g. high temperature, low humidity), and the aforementioned intra-specific nest destruction (E. Albavera pers. comm.).

\section{Nesting data collection}

Field work was conducted to monitor nesting between August and November 2009. Turtles nested during 2 study arribadas: August 14 to 18, 2009 (first arribada) and August 27 to September 4, 2009 (second arribada). Prior to the arribadas, 26 plots $\left(9 \mathrm{~m}^{2}\right.$ each, $3 \times 3 \mathrm{~m}$ ) were constructed in pairs over a lateral distance of roughly $1.75 \mathrm{~km}$ (between Stns 8 and 25.5). Since the exact location of arribada nesting

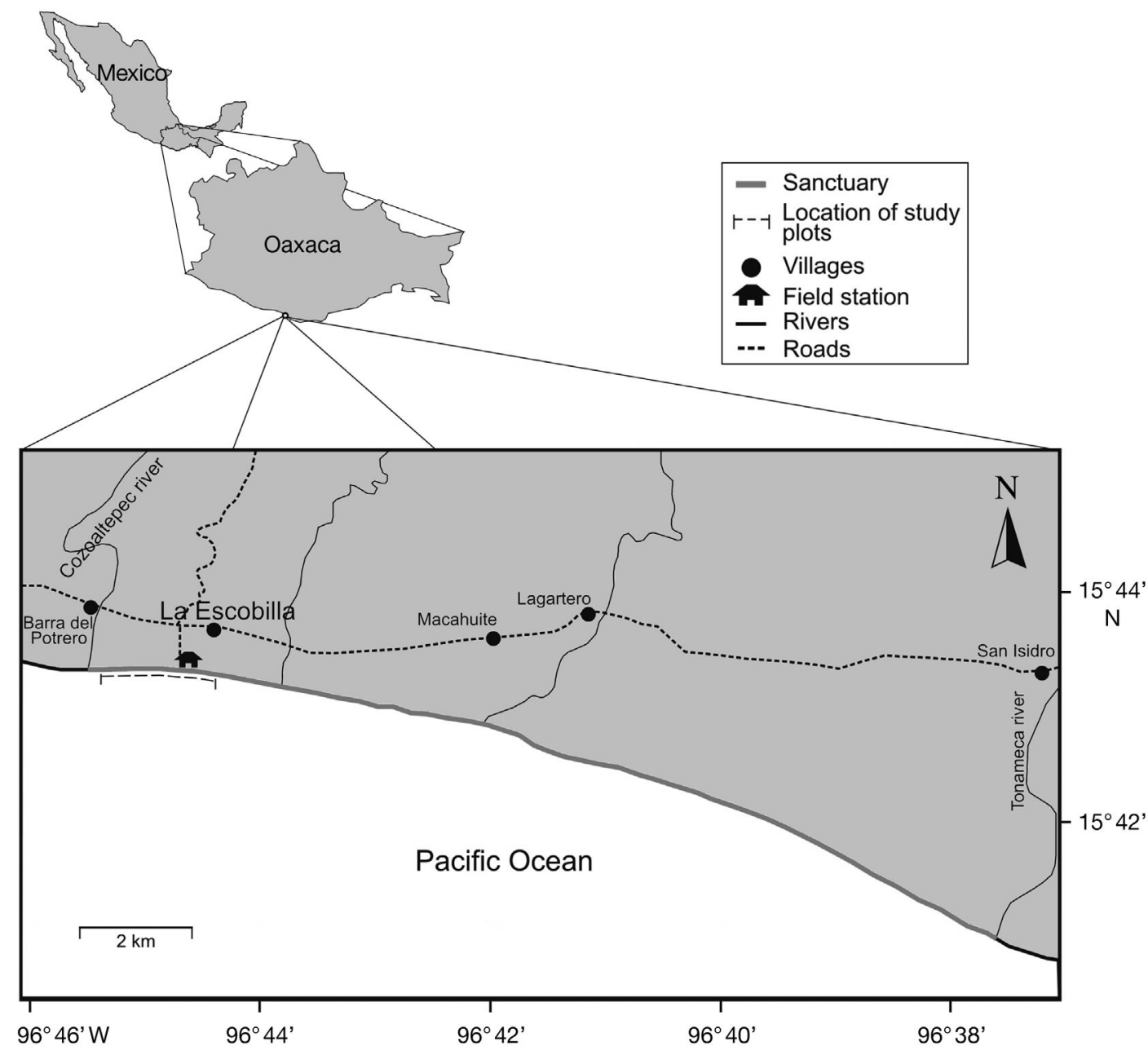

Fig. 2. Map of La Escobilla nesting beach, Mexico. Broken line indicates area of beach where study plots were located. The building symbol indicates the location of the Mexican government-sponsored field station. Map by E. Albavera, Centro Mexicano de la Tortuga 
shifts, we located plots along the mid-beach of the most frequently used nesting area to increase the likelihood of plots being used during the arribada. Plots consisted of 4 corner posts with metal fencing that could be rolled open or closed to block nesting after the arribadas. We used large-linked fencing to allow any hatchlings from prior nesting to exit the plots. While it is possible that solitary nesters may have nested in plots, we believe that there were no nests in the plots at the start of the study, based on observational records at the beach. Any solitary nests that occurred during the days of the arribada were noted by observation of females' tracks and counted during our initial plot observation. After the first arribada, which lasted 5 nights, we fenced plots to prevent potential nesting by solitary females. We reopened plots 9 nights later, during the second arribada, and then re-fenced the plots after 8 nights. Because arribada nesting occurred fairly regularly between 22:00 and 06:00 h, we refer to each $24 \mathrm{~h}$ period as a 'night,' though some prefer 'session' (Valverde et al. 1998).

Following the conventions of other arribada researchers, we began data collection in study plots once 1000 females were observed on the beach during All Terrain Vehicle (ATV) surveys (Peralta et al. 2008). Each team member was assigned to monitor 5 to 6 plots every half hour, and turtle behavior was categorized by nesting activity: excavating, egg laying, covering, and evidence of nest destruction. Nest destruction was defined as observing a female unearthing eggs, or laying or covering her nest amidst freshly broken eggs. Because the entire nesting process takes about $1 \mathrm{~h}$ (E. Albavera pers. comm.), the team observed every turtle present in study plots. Females were marked with chalk, and diagrams of female locations were drawn to avoid double-counting the same nesting activity. Observation stopped for the night when there was a marked drop in the number of females. Plots were not fenced at the end of each night because arribada nesting did not occur during the day.

Towards the end of the incubation period, which often lasts around $45 \mathrm{~d}$, the fence links were blocked with netting and plots were observed for presence of hatchlings.

\section{Data analysis}

Nest density in each plot was extrapolated from behavioral observations using methods similar to those of Cornelius \& Robinson (1985). At the mo- ment of data collection, some females had clearly nested, but others were observed excavating and had not yet laid a nest. Females commonly abort partially dug nest cavities due to external disruption or site unsuitability (E. Albavera pers. comm.); this results in incomplete nesting. Previous research at La Escobilla, conducted with similar levels of turtle-observer interaction and during a similar time of year as our study, found that $25 \%$ of females who began digging did not complete nesting $(\mathrm{n}=791$, over 3 separate arribadas and years) (Albavera \& Karam 1999 and P. E. Albavera \& M. S. Karam unpubl. data). Thus, in the absence of visual nest confirmation (subsequent observation of the nest or the same female covering a nest), the number of females observed excavating a nest cavity was adjusted downward by $25 \%$ to estimate the number of nests actually laid. We totaled the number of nests observed and estimated (from excavating females) to determine nest density per plot.

Nest density was quantified as the cumulative value of all the nests in the ground in each plot at the end of any given night. Thus, for the second arribada studied, nest density is the total number of nests present in each plot at the end of the first arribada plus the new nests added during the second arribada. To facilitate comparison across studies, we also report densities measured as nests per $9 \mathrm{~m}^{2}$.

Nest destruction was evaluated at the turtle- and plot-levels (e.g. the number of females that destroyed eggs per plot), but not at the nest- or egg-level (e.g. the number of eggs destroyed per nest), due to an inability to accurately count destroyed eggs and identify the nest from which the eggs came. The presence of eggs on the beach surface was interpreted to mean that at least one nest was negatively impacted. 'Percent destruction' was calculated nightly and over the entire arribada by dividing the number of turtles that unearthed eggs by the total number of turtles present per plot, multiplied by 100 . We have observed that a female destroys those previously laid individual eggs in her path, rather than entire nests, as she excavates her new nest cavity. Thus, we did not interpret destruction as a net loss of a nest and, therefore, did not change nest density as a function of observed (partial) destruction.

We compared nest density and nest destruction in the second arribada, during which destruction occurred on nests accumulated from both arribadas, and not in the first arribada, which had relatively little destruction. We initially calculated the correlation between the percent of females destroying eggs per plot across all nights of the arribada and the cumula- 
tive nest density per plot. However, because we had complete individual-level data (a dichotomous measure of whether or not each turtle destroyed eggs), we ran a logistic regression to make full use of all of the information collected. Using R 2.10, we ran a mixed-model logistic regression in which we used nest density at time of nesting to predict the odds of a given female destroying eggs at that time. The odds of destruction are calculated as the probability that a given turtle destroys eggs divided by the probability that a turtle does not destroy eggs; changes in the odds of destruction are positively, but not proportionally, related to the probability of destruction. The fixed-effects model formulation was: Logit (destruction) $=$ intercept + nest density. Plot was entered as a random factor to determine the effect of nest density on the probability of nest destruction at an individual turtle-level. This mixed-model approach accounts for variability in the probability of destruction attributable to random effects of plot selection by turtles (Raudenbush \& Bryk 2002).

We placed one ibutton temperature data logger (Maxim Integrated Products) at nest depth alongside each plot to monitor ambient sand temperature every $2 \mathrm{~h}$ ( $\mathrm{n}=22$ recovered). The values obtained represent estimates for a $45 \mathrm{~d}$ incubation period, as loggers were buried and nests were laid over a period of a few days.

We also excavated areas to evaluate the outcomes of second arribada nests (methodologies developed by Centro Mexicano de la Tortuga; Miller 1999). Nests were located by probing the sand with a pole every $10 \mathrm{~cm}$ to find air pockets. Predation by beetles was noted and is clearly distinguishable by shell mastication. We excavated 5 entire $9 \mathrm{~m}^{2}$ plots, as well as $1 \mathrm{~m}^{2}$ samples in the other 21 study plots. Volunteers and researchers excavated an additional thirty $1 \mathrm{~m}^{2}$ samples outside of the study area.

\section{RESULTS}

Our methods of direct observation in study plots were successful and a wide range of nest densities was observed (Table 1). Cumulative nest densities were quantified to account for destruction occurring on nests laid during both arribadas (Fig. 3). The second arribada had a significantly larger proportion of nest destruction than the first $(z=8.928, \mathrm{p}<0.0002)$, likely due to the increase in nest density per plot. There was a reasonable positive correlation between cumulative nest density and percent destruction (aggregated over all nights) per plot for the second arribada (Fig. 4; $\mathrm{r}=0.468, \mathrm{p}=0.016$ ). Using an estimated $45 \mathrm{~d}$ incubation period, over half of the nests' incubation periods overlapped, as there were only $9 \mathrm{~d}$ between arribadas. Nests would have additionally been impacted by a subsequent third arribada, if not for the fenced study plots (Peralta \& Peñaflores 2010).

Table 1. Total turtles present, estimated nest densities per $9 \mathrm{~m}^{2}$ plot ( $\mathrm{n}=26$ plots), and occurrence of intra-specific nest destruction during 2 arribadas from August to September 2009 at La Escobilla, Mexico. Nest densities are reported as both new nests laid and as cumulative nests over the 2 arribadas. For nests damaged, the numerator is the number of times that distinct nesting females were observed destroying eggs divided by the total number. It is possible that eggs observed being destroyed are from multiple nests or that the same nest could be impacted more than once. Here we interpret observation of egg destruction to indicate that one viable nest was damaged. Mean destruction per night was weighted by sample size (numbers of females present per plot)

\begin{tabular}{|lll|}
\hline Variable & First arribada & Second arribada \\
\hline $\begin{array}{l}\text { No. of turtles per } \mathbf{9} \mathbf{~ m}^{2} \text { plot } \\
\text { Mean (SD) }\end{array}$ & $21(8)$ & $28(11)$ \\
Range & $7-41$ & $8-53$ \\
Nest density per $\mathbf{9} \mathbf{~ m}^{2}$ plot & $18(6.76)$ & New: $24(9.67) ;$ \\
Mean (SD) & $6-32$ & Cumulative: $42(4.67)$ \\
Range & & $\begin{array}{l}\text { New: } 5-46 ; \\
\text { Cumulative: } 14-73\end{array}$ \\
Nest destruction & $6.09(29 / 476)$ & Cumulative nests: $15.30(168 / 1097)$ \\
Estimated nests damaged, \% & & Cumulative females and nests: 17.96 (197/1097) \\
Turtles destroying eggs, total \% & $5.12(29 / 566)$ & $6.97-28.57$ \\
$\begin{array}{l}\text { Turtles destroying eggs } \\
\text { (range of means per night, \%) }\end{array}$ & $0-15.12$ & \\
\hline
\end{tabular}




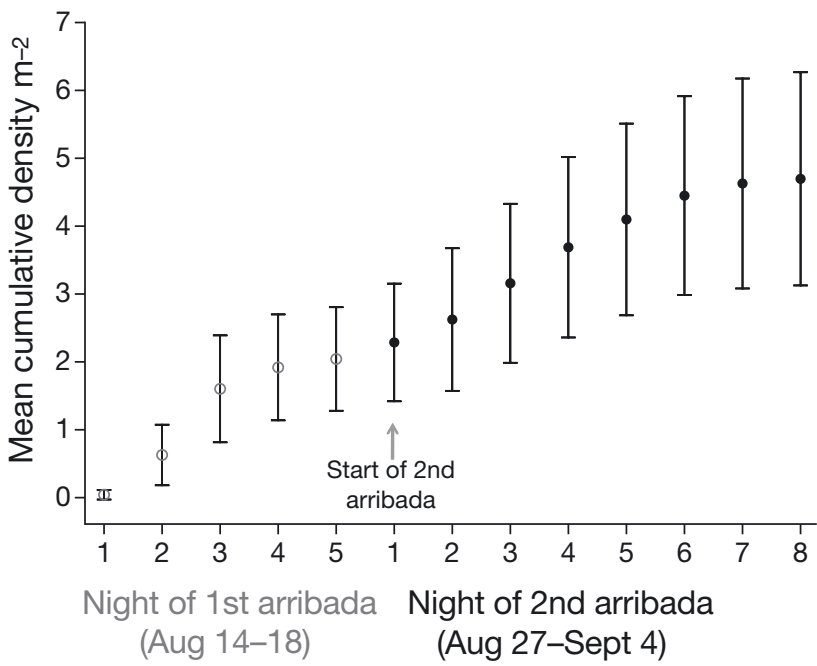

Fig. 3. Lepidochelys olivacea. Mean cumulative density of nests per $\mathrm{m}^{2}( \pm \mathrm{SD})$ per night, counted in 26 plots over 2 arribadas. Cumulative densities were quantified to account for destruction of eggs occurring in nests from either arribada. Each data point is the mean density across all plots for a given night, and $1 \mathrm{SD}$ is calculated over the mean. $\mathrm{n}$ (nests) $=476$ (first arribada), 621 (second arribada), 1097 (cumulative total)

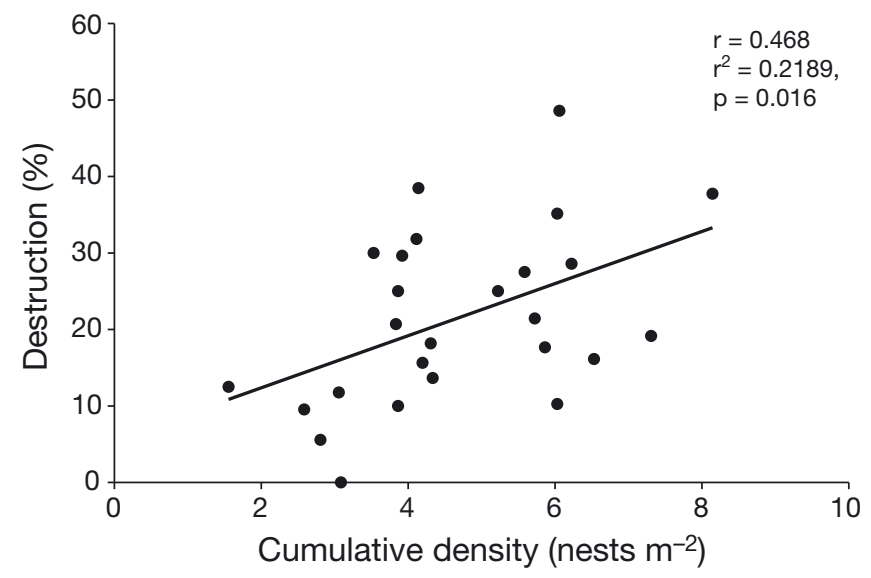

Fig. 4. Lepidochelys olivacea. Cumulative nest density (nests $\mathrm{m}^{-2}$ ) and percent destruction aggregated over the second arribada. Each data point represents a $3 \times 3 \mathrm{~m}$ plot ( $\mathrm{n}=26$ plots). Percent destruction is the number of turtles that were observed digging up eggs divided by the number of turtles nesting over all nights of the second arribada. A linear trend line illustrates the positive relationship

A mixed-model logistic regression with plot entered as a random factor revealed a negligible effect of plot on odds of destruction (plot intercept $=8.4 \times$ $10^{-12}$ ), suggesting that any effect of density on destruction was consistent across study plots. The fixed-effects portion of the model had an intercept of $-2.389(\mathrm{SE}=306, z=-7.817, \mathrm{p}<0.001)$. We found $\mathrm{a}$ positive and statistically significant effect of nest density in predicting the odds of destruction $(B=$ $0.191, \mathrm{SE}=0.068, \mathrm{p}=0.005$ ). Odds can range from zero to infinity and the odds of destruction are $\mathrm{p}$ (turtle destroys eggs)/p(turtle does not destroy), where $\mathrm{p}=$ probability. The change in odds of destruction predicted by a 1 nest increase in density $\left(\mathrm{m}^{-2}\right)$ was calculated by taking the exponent of the beta coefficient for density (0.191); the odds that an individual turtle destroys eggs increases by $21 \%$ for every additional nest in the ground per square meter $(95 \%$ confidence interval: 6 to $38 \%$ ). Using values near the average cumulative density per plot as an example, our findings predict that at a density of 4 nests $\mathrm{m}^{-2}$, the odds of a female destroying eggs would be approximately 1 to 5 . At a density of 5 nests $\mathrm{m}^{-2}$, the odds of destruction increase by $21 \%$ to 1 to 4.2 .

Unfortunately, no hatching occurred in the area of beach chosen for our study, and none of our 26 plots had successful hatching, precluding us from estimating the effects of density on egg survival. All nests sampled in the study plots had evidence of beetle predation $(n=215)$. Outside of the highly used midbeach study zone, 19 out of 30 nests sampled had evidence of successful hatching and 20 out of 30 had evidence of beetle predation. We do not report hatching success because it was difficult to determine numbers of eggshells due to fragmentation from predation. Temperature data loggers revealed mean temperatures per plot (using a $45 \mathrm{~d}$ estimation of incubation period) of $34.6^{\circ} \mathrm{C}(\mathrm{SD}=0.68)$ and $35^{\circ} \mathrm{C}$ $(\mathrm{SD}=0.69)$. A mean of 23 and $30 \mathrm{~d}$ reached $35^{\circ} \mathrm{C}$ in the first and second arribadas, respectively, across all loggers.

\section{DISCUSSION}

We successfully quantified nest densities and destruction levels of olive ridley turtles Lepidochelys olivacea during August and September, when the largest and most frequent arribadas occurred at La Escobilla, Mexico (Albavera Padilla et al. 2009). The total number of nests estimated during the first and second arribadas (95\% confidence intervals), respectively, were 186269 (146165 to 226362) and 198595 (136 107 to 261 082) (Peralta \& Peñaflores 2010). Nest destruction (when nesting females damage previously laid eggs) was a frequent occurrence, with up to $28.5 \%$ of turtles destroying eggs per night in plots. More notable is the significant predictive effect of density, wherein nest density was positively related to the odds of a given turtle destroying eggs. It became clear in our investigation that frequent arrib- 
adas and overlapping incubation periods preclude simple comparisons of impacts of nests (and turtles) on each other. Thus, the relative importance of factors that affect nests may depend on timing; this is especially true of destruction impacts, as the accumulation of nests from just 2 arribadas resulted in higher destruction levels than were evident after only 1 arribada.

Surprisingly, no hatching from the 2 arribadas (August to September 2009) was observed in the middle beach zone that was the focus of our study, including within our plots. Data collected from temperature loggers and nest excavation post-incubation suggested that predation by beetles and warm dry El Niño weather were primary determinants of nest failure. All sampled study area nests had evidence of beetle predation, indicating a major conservation concern at La Escobilla. Sand temperatures had consistently high mean maximums above the proposed $35^{\circ} \mathrm{C}$ lethal threshold for incubating olive ridley eggs (Valverde et al. 2010). The areas where hatching occurred outside the mid-beach zone were near high tide and estuaries that are likely to be cooler and have fewer beetles. Based on our observations, season, microclimate and arribada timing affect how prevalent any single factor will be in determining nest success. Because of this, we recommend monitoring a suite of factors.

Quantification of density-dependent effects is difficult and previous studies have used a variety of methods to evaluate nest density or destruction levels, depending on their goals (Table 2). Nest density is a dynamic value that changes as new nests are laid, which complicates our ability to evaluate it. This has led researchers to manipulate densities for study (e.g. Honarvar et al. 2008), to directly observe nesting activity in plots or transects (present study), or to excavate areas post-incubation (e.g. J. Jang unpubl. data). The latter method of density estimation can be difficult at arribada beaches where nests are often overlapping. We recommend that future studies quantify cumulative density, including all nests concurrently incubating, in the comparable unit of a square meter and aggregated by night, which can then be scaled up to an entire arribada if desired. In our study, cumulative values provided a more realistic picture of the quantity of nests in the ground. This is especially relevant given the nature of nesting activity at La Escobilla, with short time periods between arribadas: between 2001 and 2005, 26 arribadas had incubation periods that overlapped with 1 subsequent arribada, and 4 overlapped with 2 arribadas (Albavera Padilla 2005). Thus, true esti- mates of nest densities should take into account the fact that incubating nests are impacted by multiple arribadas, including both inter- and intra-arribada destruction.

Given its prevalence during arribadas, we believe that destruction should be regularly quantified, especially when taking into account the secondary-effects on egg survival, such as potential promotion of microbial activity and decreased oxygen availability (Fonseca et al. 2009). We recommend a standardized measurement of destruction that can be compared among studies, i.e. a method that quantifies percent females observed destroying eggs during nest construction (e.g. Girondot et al. 2002, present study). This considers destruction as a probability based on individual turtle behavior or on a turtle-level. A nestlevel approach is to tally marked nests that are destroyed (e.g. Cornelius et al. 1991), but it can be difficult, after the fact, to determine that a missing nest marker indicates destruction. Our methods required many human resources because we identified all destruction that occurred in our plots. We recommend future discussion of a representative way of extrapolating destruction levels from less frequent behavioral observations. In addition to standardizing methodologies, it is important to operationalize and clearly define 'nest destruction;' this term implies loss of an entire nest, but actually refers to individual eggs that are damaged. Although a hatchery study was conducted with artificial destruction (Caut et al. 2006), empirically obtaining specific egg-level destruction estimates remains a difficult undertaking in situ (Girondot et al. 2002). Further research at this individual egg-level would clarify reporting of destruction levels.

The lack of standardized methodology makes comparisons of our present findings with previous studies difficult. Despite these limitations, many of the estimates of nest density and destruction reported at other arribada beaches appear quantitatively similar to our findings (Table 2). Of particular interest is that Tiwari and colleagues found a significant relationship between nest density and destruction at a nonarribada nesting beach, using an analytical approach similar to ours (Tiwari et al. 2006). While densities are usually lower at non-arribada beaches, nesting models such as the above that examine spatial use by incorporating density-dependent factors could be a useful foundation for estimating hatchling production at arribada beaches. Behavioral observations, such as those reported here and in other studies (Table 2), are the first step towards quantifying population parameters for modeling. 
Table 2. Summary of recent field studies of density and/or destruction during sea turtle nesting. Studies are grouped by how data were collected during nesting by females (passive studies or manipulated densities). For each study the following information is given: common name of sea turtle species studied (leatherback: Dermochelys coriacea; green: Chelonia mydas; olive ridley: Lepidochelys olivacea), location, time (number of arribadas over which data were collected), methods (how density and/or destruction variables were measured), results (n: sample size of nests or females; empirical findings of interest rounded to the nearest tenth - percent nests impacted by intra-specific destruction, percent females observed destroying eggs), and sources of data. 'Covering' refers to a subsequent nest laid overlapping the first nest and resulting in partial destruction of the 'covered' nest. CR: Costa Rica; arr.: arribada

\begin{tabular}{|c|c|c|c|c|c|}
\hline Species & Location & Time & Methods & Results & Source \\
\hline \multicolumn{6}{|c|}{ Passive studies } \\
\hline Leatherback & $\begin{array}{l}\text { French Guiana } \\
\text { \& Suriname }\end{array}$ & 1994 & $\begin{array}{l}\text { Direct observation of percent } \\
\text { females destroying eggs }\end{array}$ & $\begin{array}{l}\mathrm{n}=2356 \text { females } \\
21.1 \% \text { females destroying eggs }\end{array}$ & $\begin{array}{l}\text { Girondot et } \\
\text { al. (2002) }\end{array}$ \\
\hline Green & $\begin{array}{l}\text { Tortuguero, } \\
\text { CR }\end{array}$ & 2000 & $\begin{array}{l}\text { Observation of nest densities and } \\
\text { destruction from previous night in plots }\end{array}$ & $\begin{array}{l}\mathrm{n}=3081 \text { nests } \\
11 \% \text { nests destroyed } \\
\text { Probability (destruction) significantly } \\
\text { increased with increasing density }\end{array}$ & $\begin{array}{l}\text { Tiwari et } \\
\text { al. (2006) }\end{array}$ \\
\hline Olive ridley & $\begin{array}{l}\text { Nancite arr., } \\
\text { CR }\end{array}$ & $\begin{array}{l}\text { 1981-1984 } \\
\text { (a) combined } \\
\text { over } 8 \text { arr. } \\
\text { (b) } 2 \text { Aug } 1981 \text {, } \\
1982 \text { arr. } \\
\text { (c) Sep } 1981- \\
1984 \text { arr. }^{c}\end{array}$ & $\begin{array}{l}\text { (a) Percent of marked nests destroyed } \\
\text { estimated from aboveground presence } \\
\text { of markers } \\
\text { (b,c) Direct observation of percent } \\
\text { females destroying eggs every } 2-3 \mathrm{~h} \\
\text { in plots }\end{array}$ & $\begin{array}{l}\text { (a) } \mathrm{n}=422 \text { nests } \\
17.1 \% \text { nests destroyed } \\
\text { (b,c) sample size not stated } \\
\text { (b) } 11.4 \% \text {, (c) } 17.8 \% \text { females } \\
\text { destroying eggs }{ }^{\mathrm{b}}\end{array}$ & $\begin{array}{l}\text { Cornelius et } \\
\text { al. (1991) }\end{array}$ \\
\hline Olive ridley & $\begin{array}{l}\text { Ostional arr., } \\
\text { CR }\end{array}$ & $\begin{array}{l}1984 \\
\text { (a) Aug \& } \\
\text { Dec arr. } \\
\text { (b) Aug arr. } \\
\text { (c) Sep arr. }\end{array}$ & $\begin{array}{l}\text { (a) Percent of marked nests destroyed } \\
\text { estimated from aboveground presence } \\
\text { of markers } \\
\text { (b,c) Direct observation of percent } \\
\text { females destroying eggs every } \\
2-3 \mathrm{~h} \text { in plots }\end{array}$ & $\begin{array}{l}\text { (a) } \mathrm{n}=200 \text { nests } \\
17.5 \% \text { nests destroyed } \\
\text { (b,c) sample size not stated } \\
\text { (b) } 22 \% \text {, (c) } 44 \% \text { females } \\
\text { destroying eggs }\end{array}$ & $\begin{array}{l}\text { Cornelius et } \\
\text { al. (1991) }\end{array}$ \\
\hline Olive ridley & $\begin{array}{l}\text { La Flor, } \\
\text { Nicaragua }\end{array}$ & $\begin{array}{l}\text { Sep 1999- } \\
\text { Jan } 2000\end{array}$ & $\begin{array}{l}\text { Compared hatching success of marked } \\
\text { single nests versus nests with destruction }\end{array}$ & $\begin{array}{l}\text { Higher hatching success in } \\
\text { single nests }{ }^{\mathrm{c}}\end{array}$ & $\begin{array}{l}\text { Von Mutius } \\
(2000)\end{array}$ \\
\hline Olive ridley & $\begin{array}{l}\text { La Flor arr., } \\
\text { Nicaragua }\end{array}$ & $\begin{array}{l}2004-2005 \\
3 \text { arr. }\end{array}$ & $\begin{array}{l}\text { Percent of marked nests destroyed } \\
\text { in control plots }\end{array}$ & $\begin{array}{l}\mathrm{n}=886 \text { nests } \\
14.5 \% \text { nests destroyed }\end{array}$ & $\begin{array}{l}\text { Honarvar } \\
\text { (2007, pers. } \\
\text { comm.) }\end{array}$ \\
\hline Olive ridley & $\begin{array}{l}\text { Ostional arr., } \\
\text { CR }\end{array}$ & 1993 & $\begin{array}{l}\text { Random direct observation of nest } \\
\text { destruction and excavation of nests }\end{array}$ & $\begin{array}{l}\mathrm{n}=2698 \text { nests } \\
7.8 \% \text { nests destroyed }\end{array}$ & $\begin{array}{l}\text { Madden et al. } \\
(2008, \text { pers. } \\
\text { comm.) }\end{array}$ \\
\hline Olive ridley & $\begin{array}{l}\text { La Escobilla, } \\
\text { Mexico }\end{array}$ & $\begin{array}{l}2009 \text { early } \\
\text { and late } \\
\text { Aug arr. }\end{array}$ & $\begin{array}{l}\text { Direct observation of nest density and } \\
\text { destruction in plots }\end{array}$ & $\begin{array}{l}\mathrm{n}=1097 \text { nests } \\
18 \% \text { nests destroyed } \\
\mathrm{n}=1293 \text { females } \\
15.2 \% \text { females destroying eggs }\end{array}$ & Present paper \\
\hline \multicolumn{6}{|c|}{ Manipulated studies } \\
\hline Leatherback & French Guiana & 2002 & $\begin{array}{l}\text { Percent emergence success of covered/ } \\
\text { covering nests. Treatments: } \\
50 \% \text { eggs destroyed } \\
25 \% \text { eggs destroyed } \\
\text { Control }\end{array}$ & $\begin{array}{l}\mathrm{n}=108 \text { nests } \\
\text { Covered/covering nests: } \\
5 \% / 1.3 \% \\
8.8 \% / 1 \% \\
14.4 \% / 24.2 \%^{\mathrm{d}}\end{array}$ & $\begin{array}{l}\text { Caut et } \\
\text { al. (2006) }\end{array}$ \\
\hline Olive ridley & $\begin{array}{l}\text { Nancite, } \\
\text { CR }\end{array}$ & $\begin{array}{l}\text { Nov 2005- } \\
\text { Jan } 2006\end{array}$ & $\begin{array}{l}\text { Hatching success in varying density } \\
\text { plots: } 2 \text { (low), } 5 \text { (medium), } \\
9 \text { (high) nests } \mathrm{m}^{-2}\end{array}$ & $\begin{array}{l}\mathrm{n}=80 \text { nests } \mathrm{e}^{\mathrm{e}} \\
\text { low } 71.6 \% \text {, medium } 55.9 \% \text {, } \\
\text { high } 29.5 \% \text { Hatching significantly } \\
\text { lower in high-density plots }\end{array}$ & $\begin{array}{l}\text { Honarvar et } \\
\text { al. (2008) }\end{array}$ \\
\hline $\begin{array}{l}\text { wari et a } \\
\text { ported. } \\
\text { ntly lowe }\end{array}$ & considered vi & rariation in the & $\begin{array}{l}\text { nount of beach disturbed by nesting fema } \\
\text { ported for those that survived erosion, pr } \\
\text { lods and results too difficult to interpret }\end{array}$ & $\begin{array}{l}\text { bFor both Cornelius studies, only un } \\
\text { tion, and destruction. }{ }^{\mathrm{c}} \text { Authors state } \\
\text { omparison. }{ }^{\mathrm{d}} \text { Caut et al. corrected em } \\
\text { s of varying densities }\end{array}$ & $\begin{array}{l}\text { hted averages } \\
\text { found signifi- } \\
\text { nce success to }\end{array}$ \\
\hline
\end{tabular}

From a population demography point of view, hatchling production is the ultimate variable to measure. Quantifying the effect of nest density on the probability of nest destruction is not only interesting from an evolutionary perspective when considering this unusual reproductive behavior (Bernardo \& Plotkin 2007), but empirically important for estimates of hatchling production and carrying capacity (e.g. 
Tiwari et al. 2010). Our study fills a gap (Table 2) by addressing both nest density and destruction at arribada beaches. The next step we recommend is to build on our study by investigating the relationship of these variables to hatchling production and beetle predation. Observation of nest destruction has already translated into management action, such as legalized egg harvest at Ostional, Costa Rica (Campbell 2007), and ongoing research will help evaluate the impacts of such management.

In the past, large numbers of turtles at arribadas created a false positive perception of their conservation status (Cornelius et al. 2007). In reality, aggregate nesting has made olive ridleys vulnerable to a variety of natural and anthropogenic stressors, including intra-specific nest destruction and egg or adult harvest for human consumption. These 2 factors are linked; the main argument for controlled egg harvest is that eggs that would otherwise be destroyed by females can instead serve as an economic resource for local communities (Campbell 1998). Taking our example, the 1990 ban on sea turtle use in Mexico ended industrial harvest (Marquez \& Carrasco-A 1996). The La Escobilla population has since increased remarkably to >1 million nests in 2000 (Marquez et al. 1996, NMFS/USFWS 2007). This quantity of nesting makes density-dependent factors more likely to influence overall hatchling production and determine future population size of this vulnerable species. After examination of previous studies that use a variety of methods, we have concluded that a standardized definition of nest density and destruction would help future comparability. Further studies will help determine the impacts of high nest density and destruction, provide scientific information to the discussion of sustainable egg harvest or other management options, and increase our understanding of potential mechanisms for improving the conservation status of olive ridleys. In the near future, quantifying density and destruction may be increasingly relevant for sea turtles at non-arribada beaches, where increased nest destruction as a result of decreased beach availability from sea level rise is a concern (Mazaris et al. 2009).

Acknowledgements. We kindly acknowledge funders for support of this project and of M. Ocana's graduate studies: AquaFish Collaborative Research Support Fellowship, British Chelonia Group, Vassar College Fellowships, Seaspace Inc., and Oregon State University's MANRRS Chapter and Dept. of Fisheries \& Wildlife. We appreciate assistance from researchers at El Centro Mexicano de la Tortuga, especially C. Peñaflores Salazar, E. Albavera Padilla, and E. Peralta Buendia. We thank all the volunteers and community members who made field work possible, especially I. Bravo,
C. Thorstenson, J. Gutiérrez, A. Munoz, and T. Huang. Thank you to Ezra Markowitz for help with this project. This manuscript was improved with helpful input from A. Evans and 4 anonymous reviewers. This research was conducted in accordance with institutional, national, and international guidelines, including approval from CONANP in Mexico and Oregon State University's IACUC.

\section{LITERATURE CITED}

Albavera Padilla E (2005) Informe de la operacion de los campamentos tortugueros del Centro Mexicano de la Tortuga entre 2001 y marzo de 2005. Secretaria del Medio Ambiente y Recursos Naturales, Mazunte

Albavera Padilla E, Karam Martinez S (1999) Identificacion de la proporcion de hembras de tortuga golfina que anidan exitosamente durante una arribada en La Escobilla, Oaxaca. In: Facultad de Ciencias del Mar (eds) Proc XVI Encuentro nacional universitario para la conservacion de tortugas marinas. Universidad Autonoma de Sinaloa, Mazatlán

Albavera Padilla E, Peñaflores CS, Peralta BE (2009) Anidaciones masivas de tortuga golfina Lepidochelys olivacea en el santuario La Escobilla, Oaxaca. Centro Mexicano de la Tortuga. In: VII Congreso nacional sobre áreas naturales protegidas de México. Comite de Areas Naturales Protegidas, San Luis Potosi

Bernardo J, Plotkin P (2007) An evolutionary perspective on the arribada phenomenon and reproductive behavioral polymorphism of olive ridley sea turtles, (Lepidochelys olivacea). In: Plotkin P (ed) Biology and conservation of ridley sea turtles. Johns Hopkins University Press, Baltimore, MD

Brook BW, Bradshaw CJA (2006) Strength of evidence for density dependence in abundance time series of 1198 species. Ecology 87:1445-1451

$>$ Bustard HR, Tognetti KP (1969) Green sea turtles: a discrete simulation of density-dependent population regulation. Science 163:939-941

Campbell L (1998) Use them or lose them? Conservation and the consumptive use of marine turtle eggs at Ostional, Costa Rica. Environ Conserv 25:305-319

Campbell L (2007) Understanding human use of olive ridleys: implications for conservation. In: Plotkin P (ed) Biology and conservation of ridley sea turtles. Johns Hopkins University Press, Baltimore, MD

> Caut S, Hulin V, Girondot M (2006) Impact of densitydependent nest destruction on emergence success of Guianan leatherback turtles (Dermochelys coriacea). Anim Conserv 9:189-197

Cornelius SE, Robinson DC (1985) Counting turtles in Costa Rica. WWF Monthly Report for August (Project 3085), WWF, Cambridge

Cornelius SE, Ulloa M, Castro J, Mata del Valle M, Robinson DC (1991) Management of olive ridley sea turtles (Lepidochelys olivacea) nesting at Playas Nancite and Ostional, Costa Rica. In: Robinson J, Redford K (eds) Neotropical wildlife use and conservation. University of Chicago Press, Chicago, IL

Cornelius SE, Arauz R, Fretey J, Godfrey MH, Marquez-M $\mathrm{R}$, Shanker K (2007) Effect of land-based harvest of Lepidochelys. In: Plotkin P (ed) Biology and conservation of ridley sea turtles. Johns Hopkins University Press, Baltimore, MD 
Fonseca LG, Murillo GA, Guadamúz L, Spínola RM, Valverde RA (2009) Downward but stable trend in the abundance of arribada olive ridley (Lepidochelys olivacea) sea turtles at Nancite Beach, Costa Rica for the period 1971-2007. Chelonian Conserv Biol 8:19-27

Gates CE, Valverde RA, Chaves AC, Ballestero J, Peskin J (1996) Estimating arribada size using a modified instantaneous count procedure. J Agric Biol Environ Stat 1: 275-287

Girondot M, Tucker AD, Rivalan P, Godfrey MH, Chevalier J (2002) Density-dependent nest destruction and population fluctuations of Guianan leatherback turtles. Anim Conserv 5:75-84

Higgins K, Hastings A, Botsford LW (1997) Density dependence and age structure: nonlinear dynamics and population behavior. Am Nat 149:247-269

Honarvar S (2007) Nesting ecology of olive ridley (Lepidochelys olivacea) turtles on arribada nesting beaches. PhD dissertation, Drexel University, Philadelphia, PA

> Honarvar S, O'Connor MP, Spotila JR (2008) Density-dependent effects on hatching success of the olive ridley turtle, Lepidochelys olivacea. Oecologia 157:221-230

Madden D, Ballestero J, Calvo C, Carlson R, Christians E, Madden E (2008) Sea turtle nesting as a process influencing a sandy beach ecosystem. Biotropica 40:758-765

Marquez R, Carrasco-A M (1996) Tortugas marinas en Mexico. In: Sanchez Palafox A (ed) Instituto Nacional de la Pesca 30th Aniversario. Secretaria del medio ambiente y recursos naturales, Mexico City

Marquez R, Peñaflores C, Vasconcelos J (1996) Olive ridley turtles (Lepidochelys olivacea) show signs of recovery at La Escobilla, Oaxaca. Mar Turtle Newsl 73:5-7

Marquez R, Carrasco MA, Jimenez MC, Peñaflores-S C, Bravo-G R (2001) Kemp's and olive ridley sea turtles populations status. In: Coyne MS, Clark RD (eds) Proc 21st annual symposium on sea turtle biology and conservation. NOAA Tech Memo NMFS-SEFSC-S28, Miami, FL

Mazaris AD, Matsinos G, Pantis JD (2009) Evaluating the impacts of coastal squeeze on sea turtle nesting. Ocean Coast Manag 52:139-145

Editorial responsibility: Jeffrey Seminoff, La Jolla, California, USA
NMFS/USFWS (National Marine Fisheries Service and US Fish and Wildlife Service) (2007) Olive ridley sea turtle (Lepidochelys olivacea) 5-year review: summary and evaluation. Jacksonville Ecological Services Field Office, Jacksonville, FL

Peralta E, Peñaflores C (2010) Avance del informe de temporada de anidacion 2009-2010 en el santuario playa de Escobilla, Oaxaca. Centro Mexicano de la Tortuga, Comision Nacional de Areas Naturales Protegidas, Mazunte

Peralta E, Tavera A, Peñaflores C, Albavera E, Sarti L (2008) Actividades de muestreo para la tortuga golfina Lepidochelys olivacea en Escobilla, Oaxaca, durante la temporada de arribadas 2008. Programa Nacional para la Conservacion de Las Tortugas Marinas. Centro Mexicano de la Tortuga, Mazunte

Raudenbush SW, Bryk AS (2002) Hierarchical linear models: applications and data analysis methods. Sage Publications, Beverly Hills, CA

Sandercock FK (1991) Life history of Coho salmon. In: Groot C, Margolis L (eds) Pacific salmon life histories. University of British Columbia Press, Vancouver, p 395-447

Tiwari M, Bjorndal K, Bolten A, Bolker B (2006) Evaluation of density-dependent processes and green turtle Chelonia mydas hatchling production at Tortuguero, Costa Rica. Mar Ecol Prog Ser 326:283-293

Tiwari M, Balazs GH, Hargrove S (2010) Estimating carrying capacity at the green turtle nesting beach of East Island, French Frigate Shoals. Mar Ecol Prog Ser 419:289-294

Valverde RA, Cornelius SE, Mo CL (1998) Decline of the olive ridley sea turtle (Lepidochelys olivacea) nesting assemblage at Nancite beach, Santa Rosa National Park, Costa Rica. Chelonian Conserv Biol 3:58-63

Valverde RA, Wingard S, Gómez F, Tordoir MT, Orrego CM (2010) Field lethal incubation temperatures of olive ridley sea turtle (Lepidochelys olivacea) embryos at a mass nesting rookery. Endanger Species Res 12:77-86

Von Mutius A (2000) Nesting and hatching success of olive ridley sea turtles in La Flor, Nicaragua. MS thesis, Ludwig-Maximilians-Universitaet, Munich

Submitted: May 16, 2011; Accepted: October 3, 2011

Proofs received from author(s): December 27, 2011 